\title{
Bilateral ligation of inferior thyroid arteries trunks in total thyroidectomy operation and its effect on postoperative serum calcium: A prospective double blind randomized study
}

\author{
Sherif Adly, $M D, F R C S(E d)$ \\ Department of Surgery, Misr University for Science and Technology Hospital, \\ Cairo, Egypt.
}

\begin{abstract}
Hypocalcemia is the most common complication following total thyroidectomy. The mechanism of this common complication is multi-factorial but whether ligating the trunk of the inferior thyroid artery plays a role or not is not fully understood. This study involves 50 consecutive patients scheduled for total thyroidectomy. Those patients were randomized into two groups, group "A" where the inferior thyroid artery trunk was ligated while in group " $B$ " it was not. Serum calcium was measured preoperatively, on the night of the operation, in the first postoperative day and 30 days after the operation. No significant difference between the two groups was found regarding serum calcium level whether in the immediate postoperative period or after 30 days of the operation. In conclusion, ligation of the trunk of the inferior thyroid artery during total thyroidectomy operation does not interfere with serum calcium level.
\end{abstract}

Key words: Inferior thyroid artery, thyroidectomy and hypocalcemia.

\section{Introduction:}

Postoperative hypocalcemia is the most common and sometimes the most severe complication observed after total thyroidectomy with a reported incidence 1.5 to $50 \% .^{1}$ This wide range was explained by the fact that they included in the study those patients with malignant as well as benign disease and also because those operations were done by general as well as endocrinal surgeons. The reasons for postoperative hypocalcemia are devascularization of the parathyroid glands during surgery, accidental removal of the parathyroid glands or hypoparathyroidism due to hematoma formation. ${ }^{2}$ It is known that almost all the blood supply of the four parathyroid glands comes from the inferior thyroid arteries. ${ }^{3}$ Some authors have questioned the effect of bilateral ligation of the inferior thyroid arteries trunks on postoperative hypocalcemia following total thyroidectomy operations. ${ }^{3,4}$

This study is a prospective double blind randomized trial to detect the effect of bilateral ligation of the trunks of inferior thyroid arteries during total thyroidectomy operations on postoperative serum calcium level.

\section{Patients and methods:}

From January 2007 to January 2009, fifty consecutive patients, 36 females and 14 males undergoing thyroid surgery at Misr University for Science \& Technology (MUST) Hospital, were included in the study. Indications of surgery were Grave`s disease $(n=10)$, toxic multinodular goiter $(n=23)$ and simple multinodular goiter $(n=17)$. Patients with Grave`s disease and toxic multinodular goiter were operated on for failure of medical treatment or for poor compliance with treatment and patients with simple multinodular goiter were operated on for pressure symptoms.

All patients with thyrotoxicosis were prepared with Neomercazole and Propranolol and were given Lugol's iodine for 14 days before the operation.

Patients were randomized into two groups 25 patients each. Randomization was done by a sealed opaque envelope technique. Group 
"A" patients had total thyroidectomy with ligation of the trunk of the inferior thyroid artery. Group "B" patients had total thyroidectomy with no ligation of the trunk of the inferior thyroid artery.

Preoperatively patients in both groups were clinically and biochemically assessed including serum calcium measurement. All patients had preoperative neck ultrasound and plain X-ray of the neck as a routine. They also had indirect laryngoscopy for preoperative vocal cords examination.

\section{Operative details:}

Surgery was started with collar skin incision and sub-platysma flaps were raised, investing layer of deep cervical fascia was incised and thyroid gland was exposed. Middle thyroid veins were doubly ligated and divided followed by the superior thyroid artery and vein. The inferior thyroid artery trunk was exposed, doubly ligated and divided in group "A" patients while in group " $\mathrm{B}$ " only the terminal branches of the artery were ligated and divided near to the gland. Recurrent laryngeal nerves were exposed and preserved in all patients. The four parathyroid glands were indentified in most of the patients and no patient needed parathyroid auto transplantation.

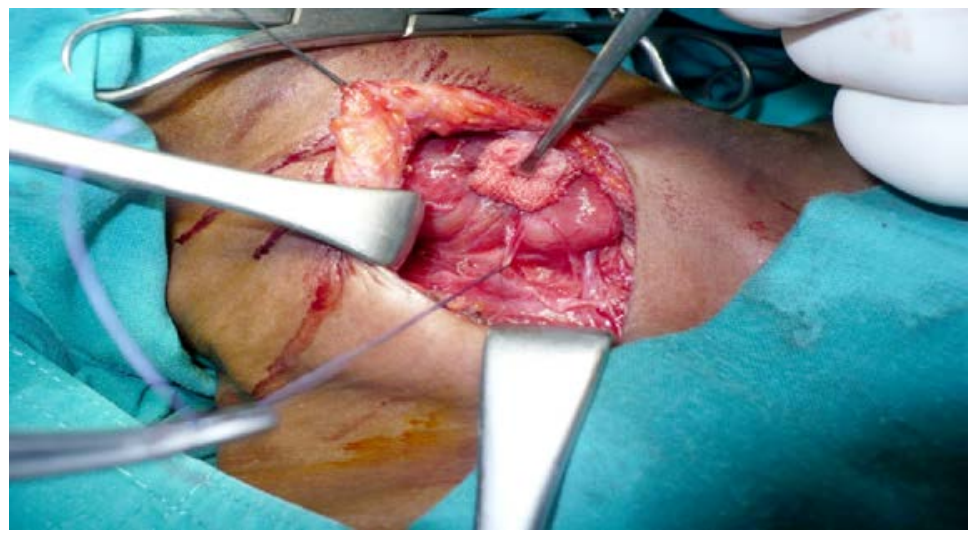

Figure (1): Shows exposure of the inferior thyroid artery.

Serum calcium was measured in the night of the operation (four hours after the end of surgery) and in the first postoperative day. Again serum calcium was measured 6 months after surgery.

Hypocalcemia was defined as serum calcium level less than $8.2 \mathrm{mg} / \mathrm{dl}$. Hypocalcemia is considered permanent when serum calcium was lower than $8.2 \mathrm{mg} / \mathrm{dl}$ six months after surgery.

Patients with documented hypocalcemia were given a combination of calcium and activated vitamin $\mathrm{D}$ orally.

All patients recruited in this study signed an informed consent and this study was approved by the ethical committee in our hospital.

\section{Results:}

There were 19 females and 6 males in group "A" and 17 females and 8 males in group "B". The difference between the two groups as regards sex distribution was insignificant.

As regards the cause of goiter in group "A" patients there were five patients with Grave's disease, ten patients with toxic multinodular goiter and ten patients with simple multinodular goiter. In group "B" patients there were five patients with Grave`s disease, thirteen patients with toxic multinodular goiter and seven patients with simple multinodular goiter. The difference between the two groups as regards the cause of goiter was not significant.

Table(1) shows the difference between the two groups as regards, age and preoperative laboratory investigations. That difference was found statistically insignificant. 
Table (1): The difference between the two groups as regards, age and preoperative laboratory investigations.

\begin{tabular}{|l|c|c|c|c|c|c|c|}
\hline & Group & Number & Mean & S.D & $\mathbf{T}$ & $\mathbf{p}$ & Significance \\
\hline Age & A & 25 & 41.84 & 8.92412 & 0.208 & 0.836 & NS \\
& B & 25 & 41.32 & 8.74033 & & & \\
\hline $\mathrm{Hb}$ & $\mathrm{A}$ & 25 & 15.676 & 1.56984 & 0.131 & 0.896 & NS \\
& $\mathrm{B}$ & 25 & 15.616 & 1.65999 & & & \\
\hline TLC & $\mathrm{A}$ & 25 & 6.6 & 1.03078 & -0.437 & 0.664 & NS \\
& $\mathrm{B}$ & 25 & 6.728 & 1.03944 & & & \\
\hline PLT & $\mathrm{A}$ & 25 & 285.04 & 16.72692 & 0.017 & 0.987 & NS \\
& $\mathrm{B}$ & 25 & 284.96 & 16.89546 & & & \\
\hline Calcium & $\mathrm{A}$ & 25 & 9.112 & 0.43139 & -0.782 & 0.438 & NS \\
& $\mathrm{B}$ & 25 & 9.22 & 0.53929 & & & \\
\hline
\end{tabular}

Hb Hemoglobin, TLC total leucocytic count, PLT platelet count, S.D standard deviation, NS not significant.

As regards postoperative calcium level, two patients (8\%) in group "A" developed hypocalcemia: for the first one, serum calcium was $7 \mathrm{mg} / \mathrm{dl}$ in the night of surgery and 6.7 $\mathrm{mg} / \mathrm{dl}$ in the first postoperative day while for the second one, serum calcium was $7.1 \mathrm{mg} / \mathrm{dl}$ in the night of surgery and $7.7 \mathrm{mg} / \mathrm{dl}$ in the first postoperative day. One of those two patients (4\%) his hypocalcemia became permanent and his serum calcium six months after surgery was $7 \mathrm{mg} / \mathrm{dl}$. In group "B", only one patient (4\%) developed temporary hypocalcemia and his serum calcium was $7.6 \mathrm{mg} / \mathrm{dl}$ in the night of surgery and $7.9 \mathrm{mg} / \mathrm{dl}$ in the first postoperative day. No patients developed permanent hypocalcemia in group "B". For those three patients in the two groups who developed hypocalcemia, intravenous calcium gluconate was given followed by a combination of calcium and activated vitamin D orally. For

those three patients serum calcium was measured every week and calcium supplement was successfully stopped in two patients one after two weeks and the other after three weeks of surgery. Only one patient in group " $\mathrm{A}$ " was maintained on calcium supplement for more than six months.

There was no recurrent laryngeal nerve injury in the two studied groups and exposure of the inferior thyroid artery did not increase the operative time.

Table(2) shows the difference between the two studied groups as regards serum calcium in the night of the operation, in the first postoperative day and 30 days after surgery. Although the mean value of serum calcium in the three readings was lower in group " $A$ " yet that difference was found statistically insignificant.

Table (2): The difference between the two studied groups as regards serum calcium in the night of the operation, in the first postoperative day and 30 days after surgery.

\begin{tabular}{|c|c|c|c|c|c|c|c|}
\hline & Group & Number & Mean & S.D & T & p & Significance \\
\hline $\mathrm{Ca} 0 \mathrm{p}$ & A & 25 & 8.564 & 0.53063 & 0.208 & -1.071 & NS \\
& B & 25 & 8.704 & 0.38131 & & & \\
\hline $\mathrm{Ca} \mathrm{1p}$ & A & 25 & 8.736 & 0.55743 & 0.131 & -0.584 & NS \\
& B & 25 & 8.812 & 0.33581 & & & \\
\hline $\mathrm{Ca} \mathrm{6m}$ & A & 25 & 8.976 & 0.47546 & -0.437 & -1.129 & NS \\
& B & 25 & 9.108 & 0.34025 & & & \\
\hline
\end{tabular}

$\mathrm{Ca} O \mathrm{p}$ is serum calcium level in the night of surgery, Ca $1 \mathrm{p}$ serum calcium is the first postoperative day, Ca $6 \mathrm{~m}$ is serum calcium 6 months after surgery, S.D is standard deviation and NS is not significant. 


\section{Discussion:}

Postoperative hypocalcemia is a major and sometimes a severe complication after total thyroidectomy. Controversies exist over the most relevant factors causing temporary and permanent hypocalcemia. Decreased serum calcium level on the night of surgery was observed in as high as $97.7 \%$ of cases. ${ }^{5}$ This phenomenon has frequently been debated and often partially explained by postoperative hemodillution. However hypocalcemia detected on the first postoperative day and afterwards is explained by most authors as a consequence of a technical cause as meticulous dissection of the recurrent laryngeal nerve causing ischemia of the parathyroid glands or some have blamed the ligation of the trunk of the inferior thyroid artery. ${ }^{6}$

Apart from the three patients who developed postoperative hypocalcemia, all other patients in the two studied groups showed a decrease in serum calcium level in the night of surgery compared to their serum calcium level measured preoperatively but this decrease in serum calcium was still within the normal range and this observation matches other studies where the incidence of decrease in the serum calcium level in the night of the operation was $97.7 \% .5$

In our study although the mean value of serum calcium in the first postoperative day was lower in group " $A$ " patients where the inferior thyroid artery trunk was ligated than in group "B" patients where the inferior thyroid artery trunk was not ligated yet this difference was not statistically significant. This is matching other studies which deny any effect for ligation of the inferior thyroid artery on the postoperative serum calcium level. ${ }^{3-5}$ Although other studies still suggest not to ligate the trunk of the inferior thyroid artery because of its effect on postoperative serum calcium level ${ }^{6-8}$ but those were all pilot studies and no prospective randomized study has supported their opinion.

Also our study showed no effect for ligation of the trunk of the inferior thyroid artery on the incidence of permanent hypocalcemia and this again matches what has been shown by the other studies. ${ }^{3-5}$

In conclusion, bilateral ligation of the trunk of the inferior thyroid artery has no effect on postoperative serum calcium level.

\section{References:}

1- Sciume C, Geraci G, Pisello F, Facella T, Li Volsi F, Licata A, Modica G: Complications in thyroid surgery: Symptomatic postoperative hypoparathyroidism incidence, surgical technique and treatment. Ann Ital Chir 2006; 77(2): 115-122.

2- Karakas E, Osei-Agyemang T, Schlosser K, Hoffmann S, Zielke A, Rothmund M, Hassan I: The impact of parathyroid auto transplantation during bilateral thyroid surgery for Grave's disease on postoperative hypocalcemia. Endocr Regul 2008; 42(23): 39-44.

3- Chaudhary IA, Afridi ZD, Samuillah Masood R, Mallhi AA: To ligate or not the inferior thyroid artery to avoid hypocalcemia after thyroid surgery. J Ayub Med Coll Abbottabad 2007; 19(2): 19-22. 4- Maralcan G, Sayin Z, Baskonu I, Gökalp A, Aybasti N: Does truncal ligation of the inferior thyroid arteries during bilateral subtotal thyroidectomy affect serum calcium levels? A prospective randomized controlled study. Int Surg 2006; 91(4): 211216.

5- Dolapçi M, Doganay M, Reis E, Kama NA: Truncal ligation of the inferior thyroid arteries does not affect serum calcium level after thyroidectomy. Eur J Surg 2000; 166(4): 286-288.

6- Milone A, Carditello A, Stilo F, Paparo D, Paparo T: Hypothyroid risk after total thyroidectomy. Chir Ital 2004; 56(5): 617 620.

7- Sakorafas GH, Stafyla V, Bramis C, Kotsifopoulos N, Kolettis T, Kassaras G: Incidental parathyroidectomy during thyroid surgery: An underappreciated complication of thyroidectomy. World $J$ Surg 2005; 29(12): 1539-1543.

8- Thomusch O, Machens A, Sekulla C, Ukkat J, Brauckhoff M, Dralle H: The impact of surgical technique on postoperative hypoparathyroidism in a bilateral thyroid surgery a multivariate analysis of 5846 consecutive patients. Surgery 2003; 133(2): 180-185. 